\title{
Getting the most from your cardiothoracic surgical training: It's all about behavior
}

\author{
Michael K. Pasque, MD
}

The Accreditation Council for Graduate Medical Education works diligently to ensure that educational metric thresholds are consistently met in all cardiothoracic (CT) surgical training programs. You can be assured that an outstanding educational experience is available in yours. So, why do some trainees exit with so much more than others? The good news is that much is left in your hands. Although all trainees start out with the best intentions, it is behavior, not intention, that determines outcome (Figure 1). Behavior is the focus of this review.

\section{DEVELOPING THE ATTITUDE AND SKILLS FOR CONTINUED LEARNING}

As CT surgery continues to rapidly evolve, CT surgeons must learn every day. If they do not systematically acquire and implement treatment advances, their patients suffer. During your early training years, you must solidly set into place the learning skills that will enable automatic and relentless career-long learning. Your success in acquiring these skills will set the trajectory for the rest of your career.

Among these skills, "being stupid" is perhaps the most essential. This is a problem. Being stupid is embarrassing. The good news is that most CT surgical educators graciously concede the fact that you don't know everything. The bad news is that this trainee privilege ends on the last day of your training. This should provide ample motivation to adopt a humble attitude in regard to learning. From that last day forward, there is a knowledge standard that the American Board of Thoracic Surgery, future colleagues, and future patients will expect you to meet. Your future patients' well-being will depend on your willingness to endure momentary embarrassment to obtain the knowledge that will save their lives. Mastering this skillset, which will serve you well for the rest of your career, mandates a little humility, and humility is hard work.

Also critical to your success is the acquisition of skills aimed at detecting and eliminating educational "black

\footnotetext{
From the Division of Cardiothoracic Surgery, Department of Surgery, Washington University School of Medicine, Barnes-Jewish Hospital, St Louis, Mo.

Received for publication April 4, 2021; revisions received June 15, 2021; accepted for publication June 22, 2021; available ahead of print July 2, 2021

Address for reprints: Michael K. Pasque, MD, Division of Cardiothoracic Surgery,

Washington University School of Medicine, Barnes-Jewish Hospital, Campus

Box 8234, 660 S. Euclid Ave, St Louis, MO 63110 (E-mail: pasquem@wustl.edu). J Thorac Cardiovasc Surg 2022;164:e257-62

$0022-5223 / \$ 36.00$

Copyright (C) 2021 by The American Association for Thoracic Surgery

https://doi.org/10.1016/j.jtcvs.2021.06.054
}

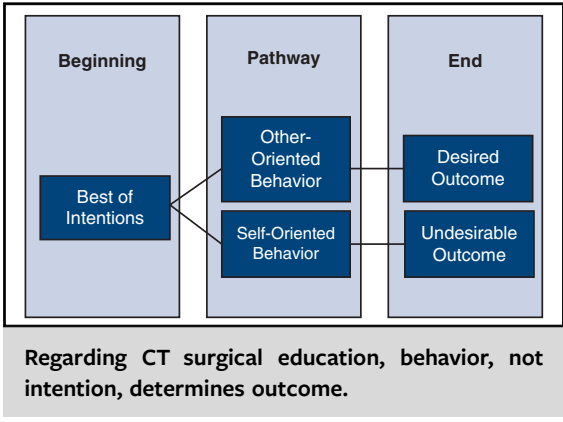

CENTRAL MESSAGE

In regard to $\mathrm{CT}$ surgical training, much is left to the trainee. Although all have the best of intentions regarding their surgical education, behavior, not intention, determines outcome.

See Commentaries on pages e263 and e264.

holes." These black holes are the small cubbyholes of your medical knowledge that remain embarrassingly empty. You may hope that the need for this information will never again darken your door. Yet you and I both know it doesn't work that way. Those black hole issues are like heat-seeking missiles. Sooner or later, they will find you.

With the advent of Google, Wikipedia, YouTube, CTS Net, STS Learning Center, and institutional CT surgical websites, there really is no excuse for tolerating these black holes. A sense of anxiety while managing a patient must signal your need to get on your computer. If you can't find the answers there, ask someone. You may find that your black hole is shared by many. But even if it seems as if you are the only one who missed out on this information, you will still have done the right thing. Take full advantage of your trainee status to embed the skillset that will habitually eliminate these deficits.

Further, if you can solidly entrench the habit of reading just one journal article a day during your training, you will help solve this black hole problem by preventing its occurrence. To make this easier, always have access to the latest journal issues in your coat pocket or on your phone. Besides current issues of our primary CT surgical journals, target articles from the past that changed the way we do 


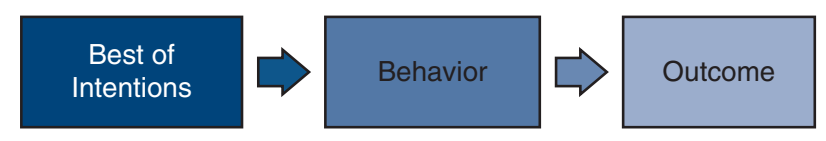

FIGURE 1. Behavior is the mediator of intention and determines outcome.

things. Then, instead of wasting that 15 -minute break between cases, zip through just one article. If you begin this daily quest during your training, your ever-increasing efficiency in extracting the critical knowledge from each manuscript will make this task less and less onerous, turning your fledgling efforts into invaluable habit. The best part: Finish that one article on your days or evenings off, and you can spend guilt-free time with your family and friends. After all, you are reading over 350 manuscripts per year, and that is enough! This habit will set you apart from your fellow trainees and set in stone the mechanism to obtain the cutting-edge knowledge that will make you great.

\section{DOING THE HARD WORK OF PREPARATION}

The reputation of our surgical subspecialty was built on extraordinary work ethic. Trainees who are unwilling to do the hard work of preparation stand out. In this regard, your reputation is only as good as your most recent performance. One bad operative performance has a way of erasing the memory of a dozen extraordinary performances. This means you don't ever just wander into the operating room unprepared. What does this hard work of preparation look like? Establish the inflexible habit of setting apart time before every procedure to thoroughly review your patient's chart. Review the patient-specific facts pertinent to the procedure, such as their CT scan, coronary angiogram, or echocardiogram. Countless life-threatening errors have been avoided by preoperative knowledge of patient-specific clinical factors.

Then review the planned procedure. In the era of easy web access to descriptions and videos of every procedure, there is simply no excuse for walking into the operating room unprepared. If your internet search doesn't reveal the answers, call a senior trainee. At most institutions, there is no mandated uniformity of operative technique, even in common procedures. The result can be considerable variation between surgeons. Every surgeon has carefully chosen their variation for a reason. Pay special attention to these differences. Each has something to offer. Remember that someday you will have your own operative plan, a carefully chosen recombination of the operative plans you observe.

Nothing moves things along more efficiently than a trainee who is well versed in these unique differences in each surgeon's technique. This knowledge facilitates your goal of keeping at least 2 steps ahead as the procedure moves along, thereby eliminating that annoying staccato interruption of the flow of the operation as the surgeon repeatedly waits for the trainee. Mastery of their order of operation will come with time, but to begin with, you must simply memorize it. Then, as your final step of preparation, sequentially visualize each step of the procedure in its proper order with the goal of having nothing catch you off guard. This is a great mental exercise that will get your mind focused and asking the right questions. Your attending surgeons will love it if you know how to do things "their way"-often resulting in a rapid and deserved evolution of your role.

Do all of this inquiry before the procedure. You can always ask questions during a procedure, but timing is key. You will win no friends if you persistently ask questions in the middle of the most complex and stress-filled portions of the procedure. If you are talking, you not only aren't helping, you're hindering. Just like anything else, you will find that half the operative battle is already won if you have done your preparation well. Do the hard work.

\section{DON'T AVOID THE DIFFICULT CASES}

We have all known CT surgical trainees who expend more energy avoiding the difficult operative cases than it takes to just do them in the first place. If this behavior is allowed to persist throughout your training, it will most certainly rise to define your career. Besides, these challenging cases are the bedrock foundation of your training. There are invaluable lessons learned in them that are simply not available elsewhere. Doing the tough cases will make the routine cases seem simple. They will prepare you to face the disasters that will invariably find you during your career. There is no free lunch. You cannot become great at doing the difficult cases without actually doing them.

To keep myself on track in this regard, I had a rule as a trainee. I tried to overcompensate in the opposite direction. I recommend the same to you. No matter what the circumstances, if it is your choice, always choose the most demanding case on the board. Find the case no one else wants-that's your case. Your attending surgeons and fellow trainees will take notice. Everybody wants to train—or train with—somebody like that. Besides, avoiding these cases is an integrity issue. If you don't do them, someone else must step up and do the hard work. You may think you can get away with it by "flying under the radar." No chance. Everyone will notice. Just do the hard work. It is always the easiest path.

\section{YOU BELONG IN THE MIDDLE OF THE CHAOS}

The same principle also applies to the many emergency scenarios that characterize our subspecialty and will certainly arise during your training. You are training to be a CT surgeon. That title carries an almost visceral expectation that you bring something special to catastrophic clinical situations. When the CT surgeon arrives, everyone assumes the ultimate "go to" person is available. 
After all, nobody deals with more life-threatening emergencies on a day-to-day basis than a CT surgeon. Sure, other subspecialties deal with their share of critically ill patients. But none of them can measure up to the cold hard fact that you are trained to start and stop the human heart every single day. You address the precarious surgical needs of the heart and lungs - and people with these surgical needs crash quicker, burn brighter, and end up a smoldering ruin more often than any other subset of patients.

As a direct result of the setting in which you spend each day, you will acquire a special skillset, an expertise in the application of an unusual set of tools. These tools uniquely allow you to fully support even those patients who have completely lost all cardiac and pulmonary function. Tucked in your back pocket is something no one else brings to these emergencies: mechanical circulatory support. The heartlung machine is the great "equalizer." Whether in the form of extracorporeal membrane oxygenation support or full cardiopulmonary bypass, it constitutes the "lifeboat" to which only you have access. It uniquely offers exactly what catastrophic medical emergencies need most: time. Time to assess the situation, get a plan, and devise a survival strategy for the patient. Everyone can take a deep breath and objectively assess the situation. Seemingly impossible situations become manageable.

What does this mean to you and your training? Everything. Your responsibility during your training goes beyond the mandate to not avoid emergency situations, and challenges you instead to run toward them. When people are running away from a sick patient's bedside, you should be moving toward it. Move into the middle of the chaos. Since you will be expected to efficiently and effectively deal with these situations, you must diligently move aggressively toward them during your training. No exceptions. Nothing trains you better for chaos than repeatedly jumping into the middle of it.

So, when the "code" alarm sounds, don't wait for them to page you. Go immediately. And when you arrive at the bedside, and there are already physicians onsite, don't leave. Stick around. Make your presence known. Not obnoxiously, but with obvious eagerness to put your skills to work. The more firepower that is brought to bear in the early moments of the fight, the more favorable the outcome. And you bring a special brand of firepower.

Further still, even if - especially if-your fellow trainees or staff CT surgeons are at the code, you still need to stick around. Not because you are needed, or just for the educational experience, but for the camaraderie. There is no greater opportunity than this to participate with, learn from, and build that very special fellowship you share with the elite membership of CT surgeons. Nothing bonds a group of trainees together like clinical disasters. Besides, there is nothing more fun than the rapid-fire, high-intensity code that a team of CT surgeons can run. There is nothing more challenging than matching wits with fellow team members in a unified effort to pull a human being back from the brink of disaster. Run toward the chaos. Then stick around and do the hard work of bringing your unique skills immediately and intensely to bear.

\section{WHAT REALLY MAKES A “GREAT" SURGEON GREAT?}

There are many misconceptions among trainees regarding the actual acquisition of the craft of CT surgery. The first - and most damaging - is that any procedure in which you are relegated to the position of "first assistant" is a waste of your time. This is particularly pertinent to our discussion, since there are one or more CT surgeons at almost every training institution who simply will never let you make the primary surgical incisions or place the most difficult sutures. You can respond to this in any number of ways. You can take on a resentful, passive-aggressive attitude toward these surgeons, from which you are guaranteed to gain very little, except a bad reputation. Instead, concede that every CT surgeon has something to teach you. Many of these surgeons who relegate you to this seemingly menial task are actually masters of their craft.

I'm not telling you to refuse the primary operative role when it is offered. Go for it. I'm just encouraging you to embrace your role as a first assistant with the same vigor. Sure, the more incisions you make and sutures you place, the better you will be at making incisions and placing sutures. But these are not the primary factors that make CT surgeons great. Overemphasis on the technical partsespecially early in your training - can actually have a detrimental impact by directing your focus away from the other important lessons. A large portion of what you must learn regarding the craft of CT surgery is best learned in the first assistant role, precisely when you are not focused on making incisions and placing sutures. Specifically, you must also master the procedure-related pathophysiological rationale, applicable clinical guideline evidence, operative logic, and "efficiency of movement" that really have nothing to do with the technical aspects of the procedure, but everything to do with being a great CT surgeon.

Over the last 4 decades, I have had the privilege of operating with some of the very best surgeons that our subspecialty has produced. "Cutting and sewing" is not what makes them great. What sets them apart is their complete command of the order and rationale of every step of every procedure. What does this mean? It means these surgeons make no wasted moves. Each step of their surgical approach is logically and seamlessly linked to both the previous and subsequent steps, such that they just seem to smoothly flow 
together. Watching these masters operate is like listening to a perfectly orchestrated symphony or watching a masterfully choreographed ballet. It is pure art.

Their procedures are masterpieces of the efficiency of movement that sets them apart, and the sage lesson these masters teach to the observant first assistant is "slow is smooth and smooth is fast." To most of us, it is counterintuitive that "slow" can ever result in fast. Only they understand that the intermediate step-"smooth"-is the true determinant of efficient perfection and therefore mediates fast. Their operations are not a flurry of activity. Speed may reign as the critical determinant of efficiency elsewhere, but assigning speed as the critical metric of CT surgical efficiency is misguided. Quite to the contrary, what they are...is smooth — and you can't teach yourself smooth. Your first encounter with the "smooth" you seek will be by observation as a first assistant.

This emphasis upon smooth perfection should not surprise you. No matter how long and complex any given procedure may be, it can always be broken down into a series of many short and relatively simple surgical moves. The key is the efficiency with which you smoothly move through the sequential perfect completion of these operative components. In CT surgery, one moves past an imperfectly completed operative step only at great peril. Steps in any direction other than perfect can only be corrected by reversing course-and there is nothing less efficient, less smooth, and more dangerous, than repeatedly going backwards. Your role as a first assistant will teach you to hate imperfection.

As a first assistant, you will learn the unique definition of "perfection" at each step: which anastomotic bleeding will stop, which air leak will heal, which valve stitch is too deep. You will know when it is time to move on... and when it is not. Further, when an imperfect step is allowed to persist, you will watch as every subsequent step is altered from that point on and how these interruptions of efficiency of movement make smooth impossible. This is the critical knowledge that you must acquire to introduce smooth into your own quest for operative efficiency, and you do this as a first assistant by worrying about what your surgeon is worrying about. First assistant cases provide a rich learning experience.

\section{YOU ARE A LIGHTNING ROD}

As CT surgeons, we routinely operate upon critically ill patients in whom inherent surgical risk is very high. And yet in our current cultural milieu, nothing short of perfect outcomes are acceptable. As a result, intellectual, physical, and emotional stress are a daily occurrence. When venting this stress, it should come as no surprise that even the nicest $\mathrm{CT}$ surgeons can reach those behavioral fringes classified as abusive. When they do, their target is usually the most frustrating object in the room. In your position as an engaged trainee, that is most often you. In that moment, despite all of the behavioral reform that our subspecialty has belatedly undergone, to them you look like a lightning rod. The "privilege" of absorbing the brunt of the abuse for the rest of the surgical team is all yours. We can act like this doesn't occur any more, but it does. Rather than ignoring it, we need to prepare you for it.

So, how are you going to respond to this sort of inappropriate behavior? A calm and appropriate response to abusive behavior can be extremely difficult. Most CT surgeons are very intelligent, and their verbal attacks can be crafted and lethal. No matter how personal the derogatory statements may seem to be, however, they usually aren't. Don't take them that way. The worst thing you can do is to respond in-kind with irritated, infuriated, or passiveaggressive behavior. Let there be no question about itthe primary factor effecting the outcome of these episodes is your response to them.

There really is only one way to respond. You need to suck it up and take the hit. There is a patient asleep on the table with their chest open who has no idea that this sort of abhorrent behavior is even possible during their procedure. They just want to get well and go home. So, when the yelling starts, heed any direct commands-but otherwise just keep working. If you are suturing something, just put your head down and keep on sewing. If assisting, refocus, concentrate, and keep working. Take the hit and keep moving forward.

Please understand that I am not defending this behavior. It is indefensible. Many of you believe that it is not only within your rights but also your responsibility to stand up to such misbehavior. I agree, $100 \%$. All I am saying is that in the middle of the surgical procedure, you have a higher calling than the preservation of your "rights"and your primary responsibility is to your patient. By its very nature, anxiety-induced abusive behavior occurs most often during the most important planned parts of the procedure or as a result of unplanned catastrophic events, such as sudden hemorrhage. There is always more critical work to be done. Your behavior at that moment simply cannot be about you. You need to respond with behavior that does not contribute to further deterioration of a situation that already has considerable potential to adversely impact your patient.

I know this is not easy. This is more of the "hard work" to which I keep referring. Yet, correctly dealing with these episodes develops invaluable mental and emotional skillsets. The ability to keep plowing forward through the procedure, without letting the enmity of the situation affect you, will allow you to rise above the emotional response of the rest of the crowd. You can deal with the surgeon's behavior later through appropriate channels - and I strongly encourage you to do this-but you will gain a stellar reputation when you demonstrate the ability, in the heat of the moment, to prevent the situation from escalating to harm. A mechanism for addressing abusive behavior is available at every 
training institution and should be formally explained to you early in your training. Pursuing this through the appropriate channels is your right and your responsibility-and the best thing you can do to help the abusive surgeon.

\section{BE NICE TO THE NONSURGEONS}

Along this same line, you may train with surgeons who mistakenly believe the intensity of their surgical endeavors legitimizes abusive behavior toward the non-surgeons who comprise the rest of the operative team. This misguided and condescending perception somehow rationalizes callous and even cruel behavior toward members of the team who they perceive to be obstructing their efforts.

An objective glance back down the course of the otherwise "illustrious" careers of these surgeons is disheartening. It reveals a road strewn with the crushed aspirations and broken hearts of those who dared to make the idealistic mistake of just trying to help these surgeons take care of their patients. Thankfully, the days of these tragically misguided bullies are nearly over. That being said, even the institution of protective measures has not yet eliminated this behavior. It may present itself in a subtle, more acceptable form, but you will still see it. When you are immersed in a culture that previously tolerated and even supported this behavior, it can sometimes be difficult to recognize that this behavior is not the norm and it is not how you are going to practice.

How are you going to respond to this behavior? First of all, don't emulate it. You are better than that. Refuse to condone it by refusing to let them "teach" you their dismissive and abusive behavior. And above all, after the case is over, move out of your comfort zone to support and actively protect the non-surgeon staff with whom you have the privilege of working. They are a vital part of your team, and the impact and importance of their careers and aspirations are every bit as important as yours.

Someday your career will also come to an end. What will you see when you look back upon your life's work? Will the ending of your career be different than that of these abusive surgeons? It all starts now during your training. I am challenging you to take a path with a completely different ending. On this path, you will realize that regardless of the number of lobectomies, valve replacements, or heart transplants you do, the people you worked with and the relationships you built are the true treasures of your career.

\section{BE NICE TO YOUR FELLOW TRAINEES}

You have probably been taught at every stage of your education that if you want to make it in life-and especially in the hyper-competitive world of CT surgery-you must, "Put yourself out there!" This gives you license to make and state your case, sometimes even forcefully, especially when you believe that you are not being treated fairly. When you haven't pursued this aggressive stance, you may have even been called "weak." Since this perspective encourages you to forcibly push yourself into every advantageous position, it has the potential to profoundly impact your training.

Those who pursue their training with this attitude do in fact "stand out." They are always running hard after their own interests, putting themselves first when positioning for scarce and competitive training opportunities. They are busy arranging to scrub on all the best cases and spend extra time on the best services, while avoiding the less attractive cases and rotations. They always have a justification for why "just this time" their learning experience is more important than that of their fellow trainees.

In sharp contrast are those who try to treat their fellow trainees as they themselves would like to be treated. Yes, I'm referring to the good old "Golden Rule." Instead of always making every situation about their own personal needs, these trainees keep their focus on everyone elsetheir patients, their attending surgeons, the non-surgeon team members, and especially their fellow trainees. They readily volunteer for the difficult and less glamorous cases that offer little educational experience and are commonly avoided. They show up early to get a head start on long clinic days. They "get" the seemingly novel thought that their fellow trainees are not competitors, but rather "comrades-in-arms," fellow travelers on a common quest that should be unifying instead of contentious. In my experience, the end result of this selfless attitude is impressively consistent. The more these trainees focus their attention upon the needs of their fellow trainees, the more they themselves seem to thrive.

A recent graduating class at our institution illustrates this perfectly. To the person, these trainees were outstanding in every respect: great clinicians, great surgeons, and clearly destined for leadership. They were fully committed to an optimal training experience. And yet their time with us was utterly without a hint of discord. I honestly don't know what they were really thinking about each other, but that doesn't really matter. Their behavior was all that mattered to me, and it was extraordinary. Each of them confronted difficult personal trials during their training. And each time, the response of the group was the same. They unfailingly went out of their way to support each other. We all noticed. They left our program as the best of friends, even getting together from all across the country to quiz each other before the oral boards. They went to war together, covered each other's backs, and came out the other end as best friends forever.

So, what's it going to be for you? How do you want it to play out later on when you see your fellow trainees at national meetings? Faces in the crowd that avert their eyes as if they didn't see you or the welcoming smiles and warm hugs of lifelong friends? Make the call. And do the hard work of looking out for each other. 


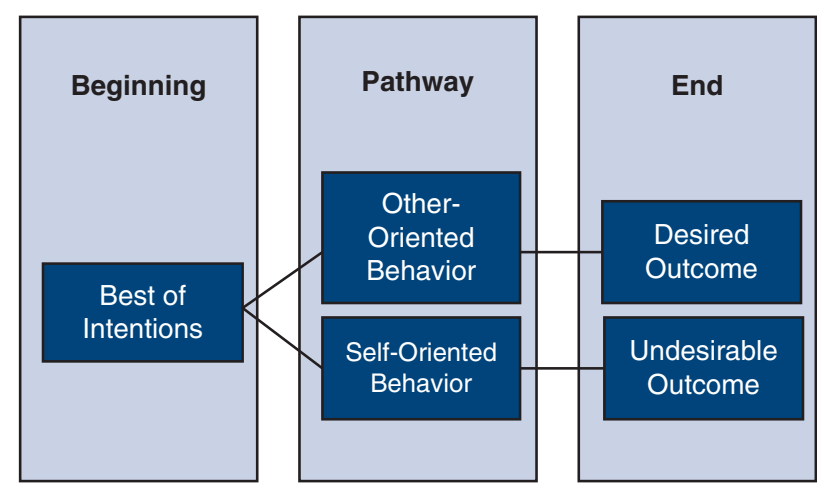

FIGURE 2. Other-oriented behavior mediates a desirable outcome.

\section{CONCLUDING THOUGHTS}

Two behavioral pathways stand before every trainee. You will—by your behavior-end up on one path or the other. Your first steps down that path will happen today. In this regard, I am sure you have the best of intentions. But behavior, not intention, will determine which path you find yourself on at the end of your training. On one pathway, you will focus your attention and efforts only on yourself and your training experience (Figure 2). On the other, you will focus upon the individuals who populate your training environment-your patients, attending faculty, nonsurgeon collaborators, and your fellow trainees. You will do the very hard work that it takes to do this very well. On this second pathway, an excellent training experience will be assured, and you will leave your training program with your hard work speaking volumes about you. You will have paid a high price, but you will be starting your career with extraordinary skills and lifelong friendships, both formed and proven in the fiery crucible of CT surgical training.

\section{Conflict of Interest Statement}

The author reported no conflicts of interest.

The Journal policy requires editors and reviewers to disclose conflicts of interest and to decline handling or reviewing manuscripts for which they may have a conflict of interest. The editors and reviewers of this article have no conflicts of interest.

As always, the author acknowledges Christina C. Pasque, MD, for her excellent editorial assistance on this manuscript and in my life.

Key Words: cardiac surgery, cardiovascular surgery, education, residency, surgical education, thoracic surgery 